\title{
Numerical Investigation of Wellbore Stability in Deepwater Shallow Sediments
}

\author{
Wei Liu $\left(\mathbb{D},{ }^{1}\right.$ Hai Lin, ${ }^{2}$ Hailong Liu, ${ }^{2}$ Chao Luo, ${ }^{1}$ Guiping Wang, ${ }^{2}$ and Jingen Deng ${ }^{1}$ \\ ${ }^{1}$ State Key Laboratory of Petroleum Resources and Prospecting and College of Petroleum Engineering, China University of Petroleum, \\ Beijing 102249, China \\ ${ }^{2}$ State Key Laboratory of Offshore Oil Exploitation, CNOOC China Limited, Tianjin Branch, Tianjin 300459, China
}

Correspondence should be addressed to Wei Liu; liuwei@cup.edu.cn

Received 20 January 2021; Revised 18 February 2021; Accepted 24 February 2021; Published 15 March 2021

Academic Editor: Meng Meng

Copyright (c) 2021 Wei Liu et al. This is an open access article distributed under the Creative Commons Attribution License, which permits unrestricted use, distribution, and reproduction in any medium, provided the original work is properly cited.

\begin{abstract}
An elaborate poro-elastoplastic numerical model has been developed in this paper to explore the stability characteristics of wellbore in shallow sediments of deepwater oil/gas wells. The combined Drucker-Prager/cap plasticity model is employed to characterize the mechanical behavior of the weakly consolidated or unconsolidated shallow sediments, by which both plastic compaction deformation and plastic shear deformation can be considered. Possible penetration of drilling fluid into the formation and its coupling to deformation have also been accounted for in the model. Using this model, deformation, stress evolution, and failure characteristics of the formation around the wellbore are analyzed in detail. Results presented in this paper demonstrate the necessity of considering the plastic compaction capability of the formation during the wellbore stability analysis of shallow sediments in deepwater. For mud pressures lower than the in situ horizontal stress, excessive wellbore shrinkage may occur if the mud pressure is too low, which, however, can be effectively mitigated through properly increasing the mud pressure even fluid penetration into the near-wellbore region may occur. It is also evidenced that, if penetration of drilling fluid into the formation is prevented, fracturing of the wellbore will not occur even the mud pressure is very high. Instead, the wellbore will expand substantially due to plastic compaction, and the deformed wellbore radius could be several times larger than the original value. However, if drilling fluid can penetrate into the formation, high pore pressure will develop within the near-wellbore region, resulting in tensile hoop stress at the wellbore and thus fracturing of the wellbore along the radial direction. The numerical results and implications in this paper are anticipated to be beneficial for the drilling operation in the shallow portion of deepwater oil/gas wells.
\end{abstract}

\section{Introduction}

The past decades have witnessed the worldwide growth in the exploration and development of deepwater and ultradeepwater oil and gas resources due to the increasing energy demand and evolving technologies $[1,2]$. Nowadays, more than $40 \%$ of the newly found oil and gas reserves are in deepwater [3]; thus, it has been expected that the share of offshore oil and gas production from deepwater would further increase in the future [1]. Recently, China is also launching more and more efforts to develop deepwater oil and gas resource.

Despite considerable technological advancements, deepwater drilling is still a nontrivial task and various challenges exist during the process of drilling due to the complex deepwater environments [4]. Among various problems, wellbore instability is a major obstacle for achieving quick and costefficient drilling. Actually, wellbore instability has long been a notorious problem in the drilling industry, irrespective of whether the well is drilled onshore or offshore, resulting in remarkable economical loss and nonproductive time. For deepwater drilling, maintaining wellbore stability is an even more difficult task since the overburden stress in deepwater is relatively low due to the long water column, resulting in narrow safe mud density windows $[4,5]$. In particular in the shallow portion, where the formation is generally weakly consolidated or even unconsolidated, special carefulness is needed to avoid wellbore instabilities like fracturing of the 
formation, lost circulation, excessive borehole closure, and borehole collapse.

Currently, common practices of wellbore stability analysis rely on the linear elasticity theory [6-8], which assume completely no plastic deformation around the wellbore and thus may overestimate the required minimum drilling mud density. Actually, for soft rocks like the shallow sediments in deepwater, it has been recognized that the wellbore can remain stable even if the surrounding rock has been loaded into a plastic state [9-11]. On the other hand, soft rocks may have experienced plastic deformation before fracturing caused by high mud pressure, which is not considered in the traditional elastic model. Thus, in recent years, various elastoplastic models have been proposed and employed for analyzing the stresses and deformations around the wellbore [10, 12-16], and borehole stability is realized by restricting either the area of the plastic region [14] or the borehole closure [10] to be less than some designated values derived from field experiences.

For deepwater drilling, wellbore stability in the shallow sediments has also been analyzed by using elastoplastic models $[3,17,18]$. These works utilized the Mohr-Coulomb model to describe the plastic behavior of the shallow sediments and to calculate the collapse pressure by dictating an allowable area of the plastic region [18] or an allowable borehole shrinkage rate [3]. For the estimation of fracture pressure of shallow sediments in deepwater, several empirical models have been proposed $[19,20]$, which directly relate the fracturing pressure to the overburden stress. If sufficient field data can be provided for calibration, these empirical models can generate fracturing pressure predictions with satisfactory accuracy. However, these models cannot reflect the mechanisms of fracturing of shallow sediments. Aadnøy and Belayneh [21] developed an elastoplastic model for analyzing the fracturing of wellbore with the plastic deformation being taken into account. They concluded that the fracture initiates at the interface of the elastic zone and the plastic zone and the fracturing pressure is increased due to the plastic deformation. Yan et al. $[3,17]$ developed a method for calculating the fracturing pressure of shallow sediment in deepwater, where they considered that formation is fractured due to the excess pore pressure caused by stress changes around wellbore. They assumed that the formation is undrained and calculated the stress state around the wellbore by considering the plastic deformation characterized by the MohrCoulomb model.

Field experiences [4] as well as theoretical and experimental studies $[17,22,23]$ have shown that the shallow sediments in deepwater are weakly consolidated or even unconsolidated, which are more like saturated soils under the in situ conditions. Thus, it is more appropriate to model the shallow sediments by using constitutive relations that are used to describe the mechanical behavior of soils. The Mohr-Coulomb model adopted in the aforementioned works $[3,17,18]$ can characterize the plastic shear deformation of the shallow sediments under high deviatoric stress. However, the plastic compaction deformation capability of the shallow sediments under high mean stress has not been taken into account.

The stress and deformation around the wellbore in shallow sediments can be complicated by the penetration of the drilling fluid into the formation. Thus, in this paper, we propose to analyze the stability of wellbores in shallow sediments of deepwater by using an elaborate poro-elastoplastic model. The formation deformation and the pore fluid flow are treated in a coupled manner. A combined Drucker-Prager/cap plasticity model is employed to govern the mechanical behavior of the shallow sediments, where the DruckerPrager model describes the plastic shear deformation and the cap model characterizes the plastic compaction deformation. The penetration of the drilling fluid into the formation and the resulting pore pressure change around the wellbore have also been taken into account in the model. By using this model, responses of the wellbore under different mud pressures are analyzed in detail to reveal the stability characteristics of wellbores in deepwater shallow sediments. Some implications for drilling stable wells in deepwater shallow sediments have been obtained.

The paper is organized as follows: Section 2 presents some general assumptions as well as basic governing equations, which is followed by descriptions of the poro-elastoplastic numerical model in Section 3. Detailed analysis results and discussions are presented in Section 4, and finally some conclusions are drawn in Section 5.

\section{General Assumptions and Basic Governing Equations}

2.1. General Assumptions. The wellbore stability problem treated in this paper is sketched in Figure 1. Prior to drilling, the formation is in equilibrium under in situ stresses, where the overburden stress $\sigma_{\mathrm{V}}$ is one of the principal stresses and the two horizontal stresses are assumed to be the same and denoted as $\sigma_{\mathrm{h}}$. The latter assumption is generally accepted since the shallow sediments have generally experienced a relatively short sedimentary period and little tectonic movements [3]. The formation rocks, i.e., the shallow sediments in deepwater, are assumed to be homogeneous, isotropic, saturated, and poorly consolidated. During the drilling process, the rock within the wellbore is removed and the support pressure to the wellbore wall is changed to be the mud pressure $p_{\mathrm{m}}$. After that, inward or outward fluid flow may occur, depending on the difference between the mud pressure and the initial pore pressure as well as possible flow barrier due to mud cake effect, wettability, and capillary effects. The complex coupled hydromechanical process generally causes a redistribution of stresses around the wellbore accompanied by elastoplastic deformation of the surrounding rocks. The problem is treated as a plane strain problem, as generally exercised in previous literatures $[3,10,16]$.

2.2. Basic Governing Equations. To illustrate the major mechanisms and processes considered in the subsequent analysis, the related basic governing equations of poroelastoplasticity are provided in the following. Firstly, pore fluid transport within the shallow sediments is described by Darcy's law:

$$
q_{i}=-\left(\frac{k}{\mu}\right) p_{, i}
$$



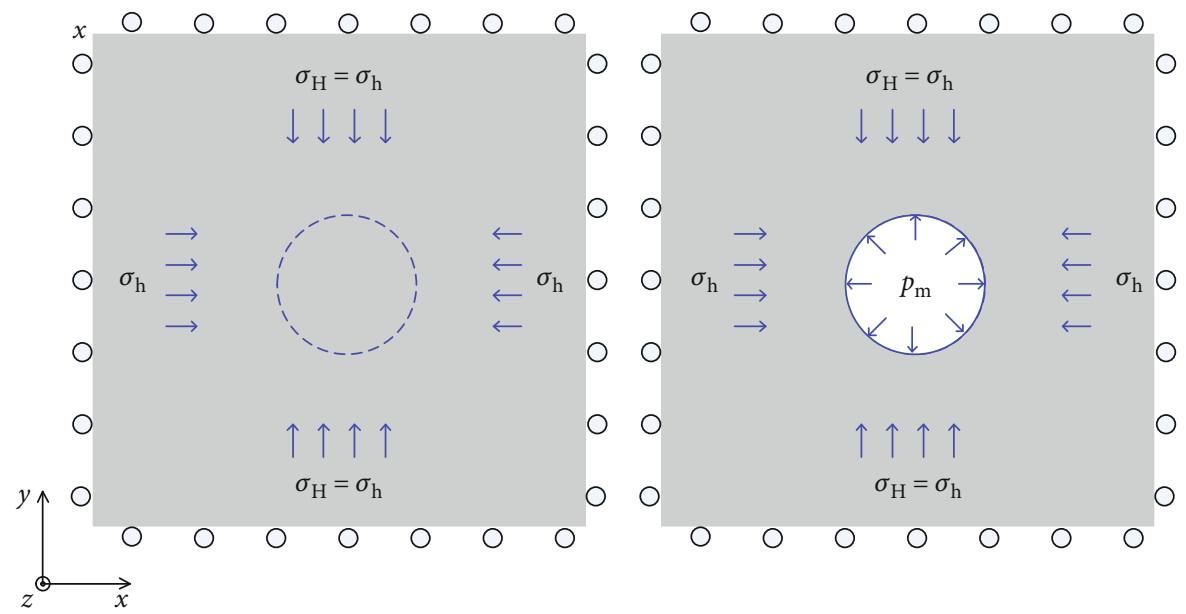

FIGURE 1: Sketch of the wellbore stability analysis problem: (a) before drilling; (b) after drilling.

where $q_{i}$ is the pore fluid seepage velocity relative to the solid skeleton, $p$ is the pore pressure, $\mu$ is the dynamic viscosity of the pore fluid, and $k$ is the intrinsic permeability of the formation. The comma in the subscript denotes the partial derivative with respect to the coordinate.

If no fluid source within the formation is considered, a local mass balance equation for the pore fluid reads [24]

$$
\dot{\zeta}+q_{i, i}=0
$$

where $\zeta$ is the variation of pore fluid content per unit reference volume of porous material, which is dictated by the following relation [24]:

$$
\zeta=\frac{p}{M}+\alpha \varepsilon_{\mathrm{v}}
$$

where $\varepsilon_{\mathrm{v}}$ is the volumetric strain, $\alpha$ is the Biot effective stress coefficient, and $M$ is the Biot modulus which can be expressed in terms of the bulk moduli of the matrix and the fluid [24]:

$$
M=\frac{K_{\mathrm{s}} K_{\mathrm{f}}}{(\alpha-\phi) K_{\mathrm{f}}+\phi K_{\mathrm{s}}},
$$

where $K_{\mathrm{s}}$ is the bulk modulus of the solid grain, $K_{\mathrm{f}}$ is the bulk modulus of the pore fluid, and $\phi$ is the porosity. The Biot effective stress coefficient can be expressed as follows [25]:

$$
\alpha=1-\frac{K}{K_{\mathrm{s}}} .
$$

In the absence of body forces, the momentum conservation equation or the equilibrium equation takes the following form:

$$
\sigma_{i j, j}=0 \text {, }
$$

where $\sigma_{i j}$ is the total stress which is related to the effective stress $\sigma_{i j}^{\prime}$ as follows [25]:

$$
\sigma_{i j}^{\prime}=\sigma_{i j}+\alpha p \delta_{i j}
$$

where $\delta_{i j}$ is the Kronecker delta.

Assuming small deformation, the strain $\varepsilon_{i j}$ is related to the displacement $u_{i}$ according to the following compatibility equation:

$$
\varepsilon_{i j}=\frac{1}{2}\left(u_{i, j}+u_{j, i}\right),
$$

while the stress is related to the strain by the following constitutive relations [24]:

$$
\sigma_{i j}=\left(K-\frac{2}{3} G\right)\left(\varepsilon_{k k}-\varepsilon_{k k}^{\mathrm{p}}\right) \delta_{i j}+2 G\left(\varepsilon_{i j}-\varepsilon_{i j}^{\mathrm{p}}\right)-\alpha p \delta_{i j} \text {, }
$$

where $G$ is the shear modulus of the rock skeleton and $\varepsilon_{i j}^{\mathrm{p}}$ the plastic strain.

As mentioned in Introduction, the shallow sediments are generally weakly consolidated or even unconsolidated, exhibiting mechanical behaviors that are more similar to those of saturated soil. Besides plastic shear deformation under high deviatoric stress, these soft rocks may experience considerable plastic compaction deformation under high mean effective stress. The latter behavior may influence the drilling-induced stress redistribution around the wellbore in shallow sediments of deepwater and thus the stability characteristics of the wellbore. To appropriately characterize the mechanical behavior of the shallow sediments as well as its possible influence on the wellbore stability, we employ a combined Drucker-Prager/cap plasticity model to describe the plastic behavior of the shallow sediments, by which both the plastic shear deformation and plastic compaction deformation can be taken into account. The yield surface of the Drucker-Prager/cap plasticity model employed in this paper 


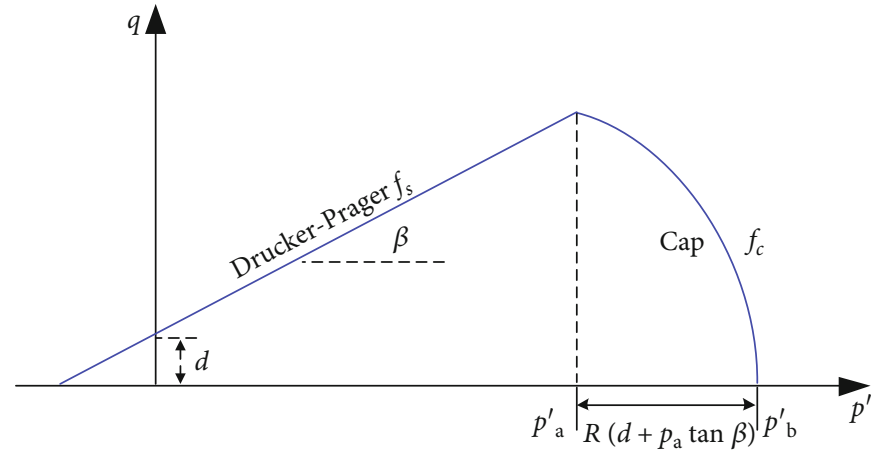

Figure 2: Yield surface of the Drucker-Prager/cap plasticity model in the $p^{\prime}-q$ plane.

consists of two parts as shown in Figure 2. Plastic shear deformation occurs when the stress state reaches the Drucker-Prager yield surface indicated in Figure 2 and given by the following expression [26]:

$$
f_{s}=q-p^{\prime} \tan \beta-d=0,
$$

where $\beta$ and $d$ are the friction angle and the cohesion in the $p^{\prime}-q$ plane, respectively. $p^{\prime}$ and $q$ are the mean effective stress and deviatoric stress, respectively, defined as

$$
\begin{gathered}
p^{\prime}=\frac{1}{3}\left(\sigma_{1}^{\prime}+\sigma_{2}^{\prime}+\sigma_{3}^{\prime}\right) \\
q=\sqrt{\frac{1}{2}\left[\left(\sigma_{1}^{\prime}-\sigma_{2}^{\prime}\right)^{2}+\left(\sigma_{2}^{\prime}-\sigma_{3}^{\prime}\right)^{2}+\left(\sigma_{1}^{\prime}-\sigma_{3}^{\prime}\right)^{2}\right]}
\end{gathered}
$$

where $\sigma_{1}^{\prime}, \sigma_{2}^{\prime}$, and $\sigma_{3}^{\prime}$ are the principal effective stresses.

On the other hand, plastic compaction deformation occurs when the stress state reaches the elliptical cap yield surface in Figure 2 which is expressed as [26]:

$$
f_{c}=\sqrt{\left(p^{\prime}-p_{a}^{\prime}\right)^{2}+(R q)^{2}}-R\left(d+p_{a}^{\prime} \tan \beta\right)=0,
$$

where $R$ is the material parameter that controls the shape of the cap field surface. The cap yield surface hardens (expands) as the volumetric plastic strain $\varepsilon_{\mathrm{v}}^{\mathrm{pl}}$ increases, which reflects the phenomenon that compaction yielding strength of soft rocks increases as they are compacted. The hardening law is given as a function relating the compaction yielding strength $p_{b}^{\prime}$ and the volumetric plastic strain $\varepsilon_{\mathrm{v}}^{\mathrm{pl}}$, which is generally of the following exponential form [26]:

$$
p_{b}^{\prime}=p_{b 0}^{\prime} \exp \left(\lambda \varepsilon_{v}^{p l}\right)
$$

where $p_{b 0}^{\prime}$ is the initial compaction yield strength and the coefficient $\lambda$ characterizes the plastic compaction capability of the soft formation which can be determined through laboratory experiments, e.g., the isotropic consolidation test with loading-unloading-reloading cycles. Larger $\lambda$, indicating that the compaction yield strength $p_{b}^{\prime}$ increases more rapidly with

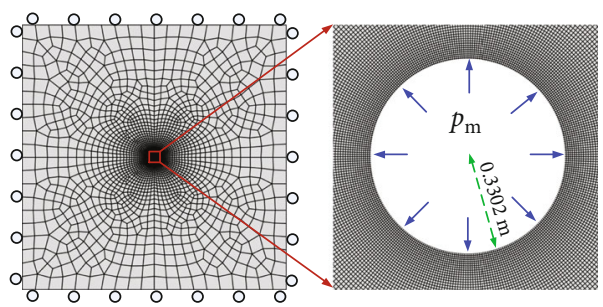

Figure 3: Finite element mesh of the wellbore stability analysis model in this paper.

volumetric plastic strain $\varepsilon_{\mathrm{v}}^{\mathrm{p}}$, means lower plastic compaction capability.

Accordingly, the flow potential surface of the DruckerPrager/cap plasticity model is composed of two parts. For the Drucker-Prager plasticity, a nonassociated flow is assumed and the potential function is expressed as [26]

$$
F_{s}=\sqrt{\left[\left(p_{a}^{\prime}-p^{\prime}\right) \tan \beta\right]^{2}+q^{2}}
$$

while an associated flow is assumed for the cap plasticity, and the potential function $F_{c}$ is [26]

$$
F_{c}=\sqrt{\left(p^{\prime}-p_{a}^{\prime}\right)^{2}+(R q)^{2}} \text {. }
$$

\section{Model Descriptions}

The fully coupled poro-elastoplasticity equations presented in Section 2 can be solved numerically using the finite element method. In this paper, a well-validated finite element code, ABAQUS [27], has been chosen to solve the coupled poro-elastoplasticity equations and to construct an elaborate numerical model to investigate the stability characteristics of boreholes drilled in the shallow sediments of deepwater.

Consider a deepwater well with a water depth of $1275.5 \mathrm{~m}$. The shallow sediments within the $1275.5 \mathrm{~m} \sim 1658 \mathrm{~m}$ (0 382.5 m bsf) well interval mainly consist of clays and clayey silts which are weakly consolidated/unconsolidated. Stability of wellbore within this interval is taken to be analyzed. The finite element mesh of the developed numerical model is shown in Figure 3. The initial borehole radius is 
$0.3302 \mathrm{~m}$ (13 inches). The size of the model domain is $50 \mathrm{~m}$ $\times 50 \mathrm{~m}$, which was intentionally chosen to be large enough for eliminating the boundary effects in the pore fluid flow modeling. If only mechanical behavior is considered, a much smaller model could be utilized. The model is discretized into 28547 nodes and 9398 8-node plane strain quadratic elements with a full quadrature scheme. The mesh within the near-wellbore region is highly refined to better characterize the deformation and stresses within that region.

The modeling job is generally performed in the following sequential steps:

Step 1. Initial equilibrium. Before drilling, the in situ stresses are applied in the model as initial stress conditions. The displacements at the external boundaries are fixed, and the pore pressure within the model is assigned to be the initial pore pressure. A support pressure equal to the isotropic in situ horizontal stress is applied at the wellbore surface. After applying these boundary and initial conditions, an equilibrium analysis is performed to check whether the initial stress state is in equilibrium with the boundary constraints and ensure that the model resembles the actual in situ state of the formation before drilling.

Step 2. Drilling. Excavation of the formation rock within the wellbore is modeled by gradually changing the support pressure to the wellbore from the initial value, i.e., the in situ horizontal stress, to the adopted mud pressure $p_{\mathrm{m}}$, since the drilling operation is instantaneous in nature. Even if it is possible, penetration of drilling fluid into the formation during this short period is little. Thus, in this paper, drilling operation is modeled by a single step without considering the pore fluid flow, and during this step, the pore pressure within the model is held constant as the initial pore pressure.

Step 3. Fluid exchange. After the drilling operation, fluid exchange between the wellbore and the near-wellbore formation may occur if the mud pressure is different from the initial pore pressure. To model this phenomenon and its influence on the wellbore stability, another step is implemented immediately after the drilling step to simulate the coupled fluid flow and deformation process. In this step, pore pressure at the wellbore surface is needed to be provided as a boundary condition. Generally, the pore pressure at the wellbore surface $p_{\mathrm{w}}$ is not necessarily equal to the mud pressure $p_{\mathrm{m}}$ since a flow barrier may form on the wellbore surface due to the mud cake, wettability, and capillary effects [5]. It is difficult to quantitatively characterize the effect of each of these factors on the flow barrier. Thus, existing researches either treated two extreme cases, i.e., no barrier and perfect barrier $[5,21]$, or introduced the following coefficient to characterize the effect of the flow barrier [14]:

$$
\delta=\frac{p_{\mathrm{m}}-p_{\mathrm{w}}}{p_{\mathrm{m}}-p_{0}}
$$

where $\delta$ ranges from 0 for no barrier to 1 for perfect barrier.
TABLE 1: Parameters used in the analysis of wellbore stability in deepwater shallow sediments.

\begin{tabular}{lc}
\hline Parameter & Value \\
\hline Vertical in situ stress $\sigma_{\mathrm{V}}(\mathrm{MPa})$ & 20.9 \\
Horizontal in situ stress $\sigma_{\mathrm{h}}(\mathrm{MPa})$ & 19.4 \\
Initial pore fluid pressure $p_{0}(\mathrm{MPa})$ & 16.9 \\
Elastic modulus $E(\mathrm{MPa})$ & 300 \\
Poisson's ratio $v$ & 0.35 \\
Angle of friction in the $p-q$ plane $\beta\left(^{\circ}\right)$ & 30.0 \\
Cohesion in the $p-q$ plane $d(\mathrm{MPa})$ & 0.63 \\
Coefficient $R$ in the cap field function & 1.0 \\
Biot's coefficient $\alpha$ & 1.0 \\
Dynamic viscosity of the pore fluid $\mu(\mathrm{Pa} \cdot \mathrm{s})$ & 0.001 \\
Initial permeability $k_{0}(\mathrm{mD})$ & 10.0 \\
Coefficient $a$ in equation $(17)$ & 15.0 \\
Initial porosity $\phi_{0}$ & $30 \%$ \\
Bulk modulus of the pore fluid $(\mathrm{GPa})$ & 2.2 \\
Coefficient $\lambda$ in equation $(13)$ & 10.2 \\
\hline
\end{tabular}

In this paper, like Aadnoy [5] as well as Aadnøy and Belayneh [21], we also consider two extreme cases: perfect barrier and no barrier on the wellbore. For the former case, only drilling operation in step 2 is implemented and the subsequent step 3 for coupled fluid flow and deformation is ignored. For the latter case, a subsequent coupled fluid flow and deformation process is modeled and the pore pressure at the wellbore surface $p_{\mathrm{w}}$ is set to be equal to the mud pressure $p_{\mathrm{m}}$.

Another factor influencing the pore fluid flow is the permeability change due to the plastic deformation. Permeability increase due to shear yielding-induced dilation has been considered in the wellbore stability analysis $[14,16]$, where constant ratios between permeability of the plastic region and that of the elastic region lager than one were assumed. For poorly consolidated/unconsolidated rocks, plastic compaction deformation near the wellbore may be considerable, which may decrease the permeability. To take both of these two effects into account, in this paper, we propose to use an approximate expression to relate the permeability to the porosity. From laboratory experiments, Bryant et al. [28] showed that the permeability of unconsolidated marine shallow sediments from the Gulf of Mexico is exponentially dependent on the porosity, from which the following relation can be derived:

$$
k=k_{0} e^{a\left(\phi-\phi_{0}\right)},
$$

where $k_{0}$ is the initial permeability, $\phi_{0}$ is the initial porosity, $a$ is a coefficient mainly depending on the clay content and is generally within the range of 14.18 17.51 according to Bryant et al. [28]. In this paper, the permeability-porosity relation dictated in equation (16) is implemented into the ABAQUS code using the user subroutine functionality to describe the variation of the permeability of shallow 


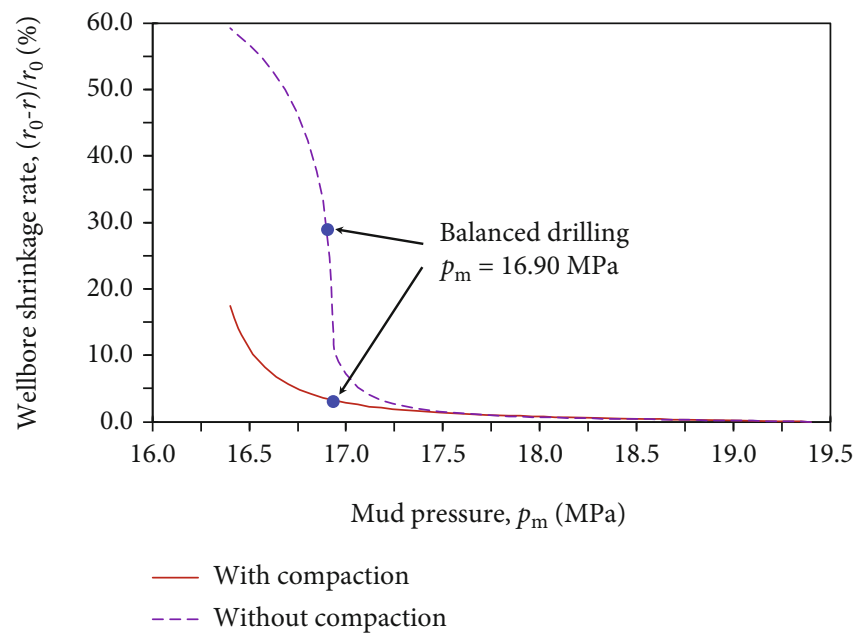

FIGURE 4: Wellbore shrinkage rate $\left(r_{0}-r\right) / r_{0}$ varying with mud pressure $p_{\mathrm{m}}$ (perfect flow barrier).

sediments around the wellbore. Primary parameters used in the analysis are listed in Table 1.

\section{Analysis Results and Discussions}

Using the poro-elastoplastic numerical model described in Section 3, two major sets of analysis are performed. In the first set, deformation and stresses around the wellbore under mud pressures lower than the in situ horizontal stress are calculated to evaluate the wellbore shrinkage and collapse characteristics of the wellbore in deepwater shallow sediments, while in the second set, mud pressures higher than the in situ horizontal stress are considered to explore the mechanisms and characteristics of wellbore fracturing in deepwater shallow sediments. For each of these two sets, both perfect flow barrier and no flow barrier on the wellbore surface are considered, respectively. Detailed analysis results, discussions, and implications are presented in the following.

4.1. Stability of the Wellbore in Deepwater Shallow Sediments under Mud Pressures Lower Than the In Situ Horizontal Stress. When the mud pressure is lower than the in situ horizontal stress during the drilling process, the initial equilibrium is lost and the wellbore tends to deform inwards, resulting in wellbore shrinkage. Shown in Figure 4 is the wellbore shrinkage rate varying with different mud pressures for the perfect flow barrier case. For comparison, we also calculated the results considering only shear plasticity. As expected, the wellbore shrinkage rate firstly increases with decreasing mud pressure mildly either with or without considering the plastic compaction deformation. However, with further decreasing mud pressure, the wellbore shrinkage rates for the two cases both increases rapidly, and one can notice that the wellbore shrinkage rate without plastic compaction is remarkably larger than that with plastic compaction under the same mud pressure. When the mud pressure is $16.4 \mathrm{MPa}$, which means drilling slightly underpressure, the wellbore shrinkage rate amounts to $17.5 \%$ with plastic compaction and $59.3 \%$ without plastic compaction. Thus, it can be concluded that the plastic compaction capability of

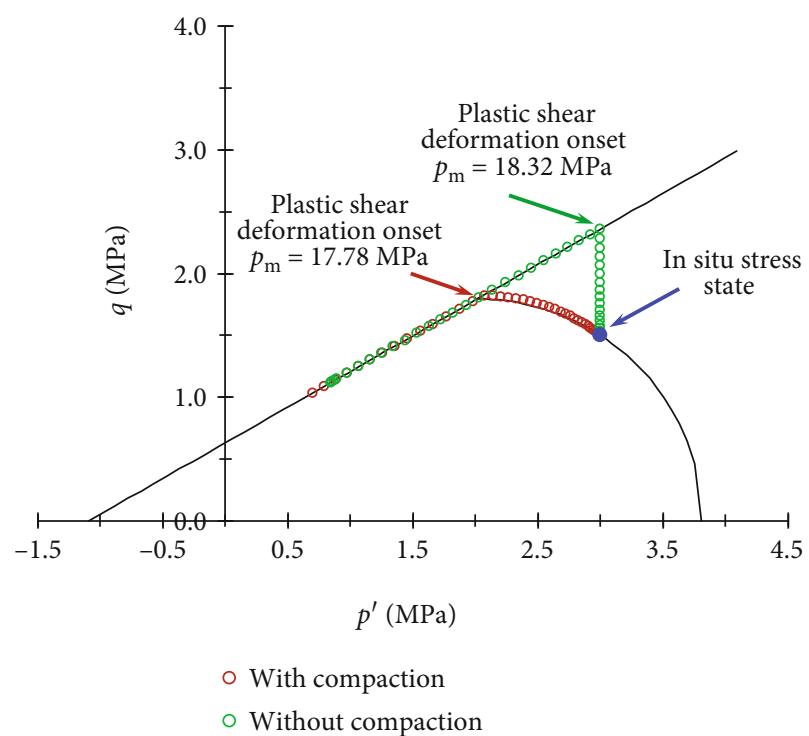

FIGURE 5: Effective stress paths experienced by a point on the wellbore surface during the drilling process (perfect flow barrier and $p_{\mathrm{m}}$ of $\left.16.94 \mathrm{MPa}\right)$.

the shallow sediments in deepwater has significant influence on the deformation of the borehole and should be carefully evaluated for realistic prediction of the stability characteristic of the wellbore drilled in the shallow portion of deepwater wells. The results presented in Figure 4 can be used to determine the lowest required mud pressure during the drilling process by assigning an allowable wellbore shrinkage rate. According to some researchers $[3,29]$, the wellbore shrinkage rate less than $2 \%$ is considered not to influence the safety of drilling. From Figure 4, balanced drilling, i.e., $p_{\mathrm{m}}=16.9$ $\mathrm{MPa}$, will generate a wellbore shrinkage rate of $3.50 \%$, and the mud pressure corresponding to a wellbore shrinkage rate of $2 \%$ is $17.19 \mathrm{MPa}$.

Figure 5 depicts the typical effective stress paths in the $p^{\prime}-q$ plane experienced by a point on the wellbore surface during the drilling process, while Figure 6 presents the 


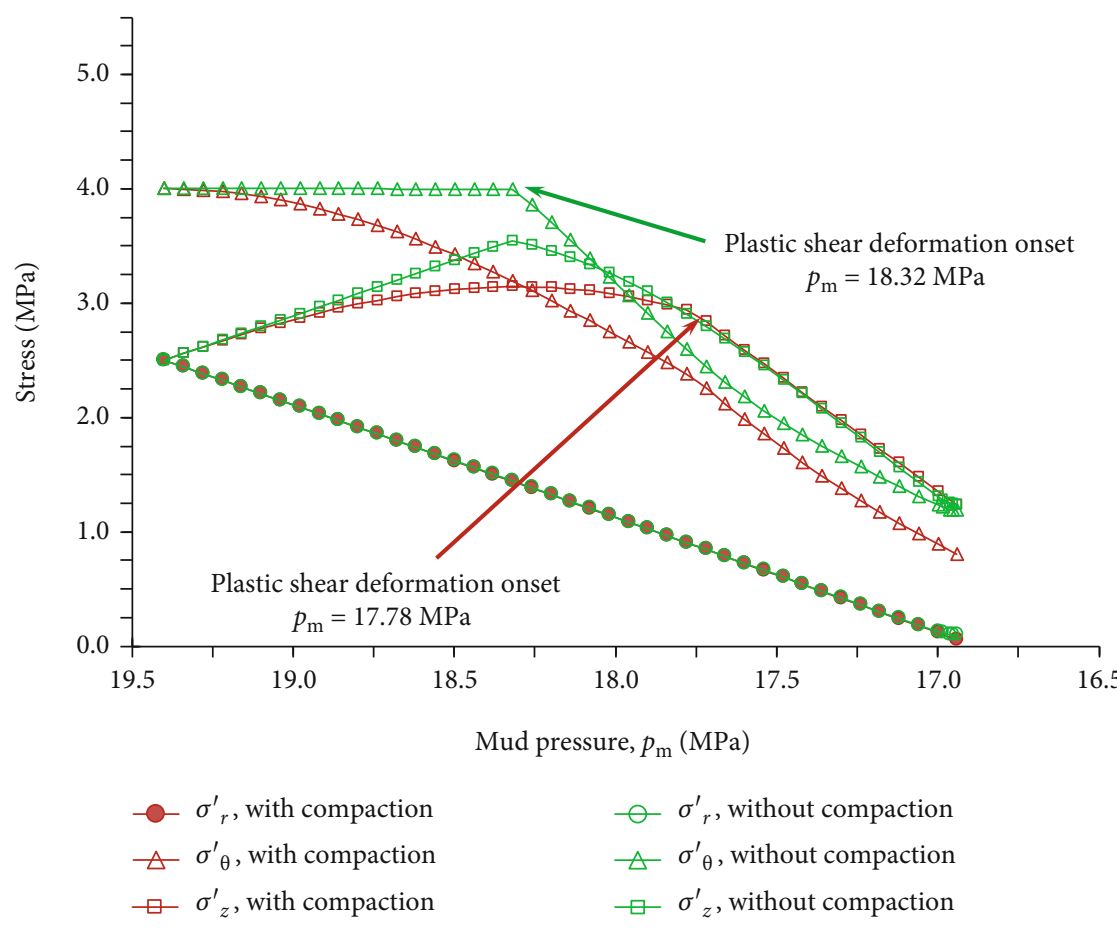

FIGURE 6: Effective stress evolution at a point on the wellbore surface during the drilling process (perfect flow barrier and $p_{\mathrm{m}}$ of $16.94 \mathrm{MPa}$ ).

evolution of the three effective principal stress components (radial effective stress $\sigma_{r}^{\prime}$, hoop effective stress $\sigma_{\theta}^{\prime}$, and vertical effective stress $\sigma_{z}^{\prime}$ ) at the same point. The final mud pressure $p_{\mathrm{m}}$ is $16.94 \mathrm{MPa}$, and the perfect flow barrier is modelled. From Figure 5, it can be clearly seen that, if plastic compaction is considered, the stress path firstly follows the cap field surface, which means that the wellbore firstly experiences plastic compaction deformation as the support pressure decreases from the initial horizontal stress 19.4 MPa. In this process, the hoop effective stress $\sigma_{\theta}^{\prime}$ increases firstly and then decreases nonlinearly while the vertical effective stress $\sigma_{z}^{\prime}$ decreases nonlinearly. When the support pressure decreases to a value of $17.78 \mathrm{MPa}$, the stress path hits the DruckerPrager shear yield surface, and thus, plastic shear deformation initiates at the wellbore surface. After that, both the hoop effective stress $\sigma_{\theta}^{\prime}$ and the vertical effective stress $\sigma_{z}^{\prime}$ decrease with decreasing support pressure, and the plastic shear yielding region will expand and the wellbore radial inward displacement increases rapidly with further decreasing support pressure until it reaches the employed mud pressure, i.e., 16.94 $\mathrm{MPa}$. In comparison, if plastic compaction of the formation is not considered, in Figure 5, the stress path goes upward vertically before reaching the DruckerPrager plastic shear yield surface, which implies that the mean effective stress does not change while the deviatoric stress increases continuously. During this elastic deformation process, Figure 6 shows that the hoop effective stress $\sigma_{\theta}^{\prime}$ increases linearly while the vertical effective stress $\sigma_{z}^{\prime}$ remains constant. When the support pressure is reduced to the value of $18.32 \mathrm{MPa}$, the stress path reaches the Drucker-Prager shear yield surface, inducing plastic shear deformation within the near-wellbore region. After that, like the case of not considering plastic compaction, both the hoop effective stress $\sigma_{\theta}^{\prime}$ and the vertical effective stress $\sigma_{z}^{\prime}$ decrease as the support pressure further decreases. From Figures 5 and 6, it can be seen that ignoring the possible plastic compaction capability of the deepwater shallow sediments will exaggerate deviatoric stress and the mean effective stress before plastic shear deformation occurs, resulting in the earlier onset of plastic shear deformation and the final wellbore deformation, as indicated in Figure 4.

Figure 7 depicts the distributions of the radial stress, hoop stress, and vertical stress, as well as the equivalent plastic strains corresponding to the plastic shear yielding and plastic compaction yielding along the radial direction. The final mud pressure $p_{\mathrm{m}}$ is $16.94 \mathrm{MPa}$, and the perfect flow barrier is modelled. From Figure 7, it can be found that the nearwellbore region can be roughly divided into three distinct zones if plastic compaction is considered. The sediments within zone I have firstly experienced plastic compaction yielding and then plastic shear yielding, while within zone II, only plastic compaction yielding occurs. Zone III represents the region of elastic deformation hat has not been disturbed by drilling. In comparison, if plastic compaction is not considered, there is only a plastic shear yielding zone around the near wellbore. Figure 7 also shows that the stresses within zone I and zone II are relaxed due to shear yielding and compaction yielding, which is typical for elastoplastic analysis of wellbore stability [10].

If no flow barrier exists at the wellbore, fluid exchange between the wellbore and the formation will result in pore pressure change within the near-wellbore region, which may lead to additional deformation. Figure 8 provides the wellbore shrinkage rate varying with different mud pressures for the no 


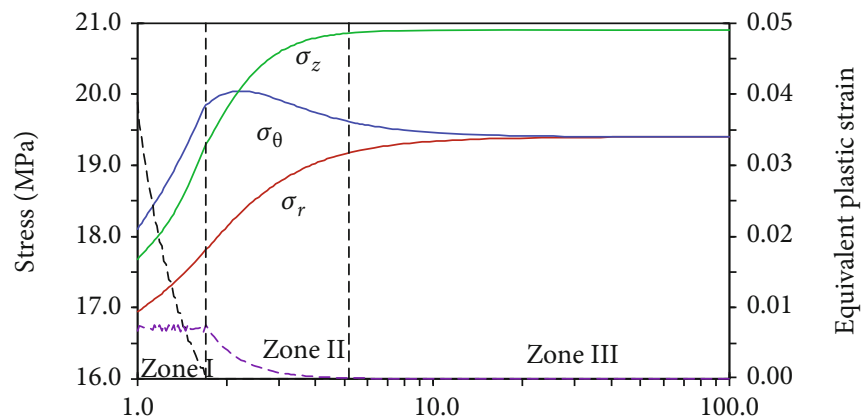

Normalized radial distance, $r / r_{0}$

- - Shear equivalent plastic strain

- - Compaction equivalent plastic strain

(a)

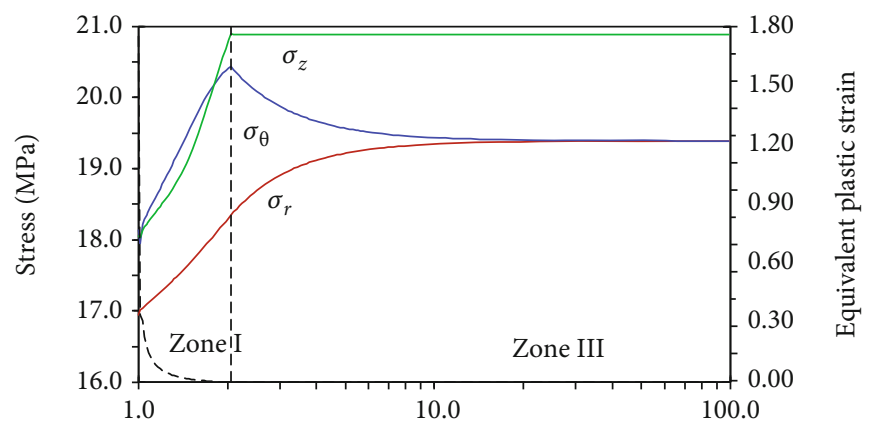

Normalized radial distance, $r / r_{0}$

-- - Shear equivalent plastic strain

(b)

FiguRE 7: Distributions of the radial stress, hoop stress, and vertical stress, as well as the equivalent plastic strains along the radial direction: (a) with compaction and (b) without compaction (perfect flow barrier and $p_{\mathrm{m}}$ of $16.94 \mathrm{MPa}$ ).

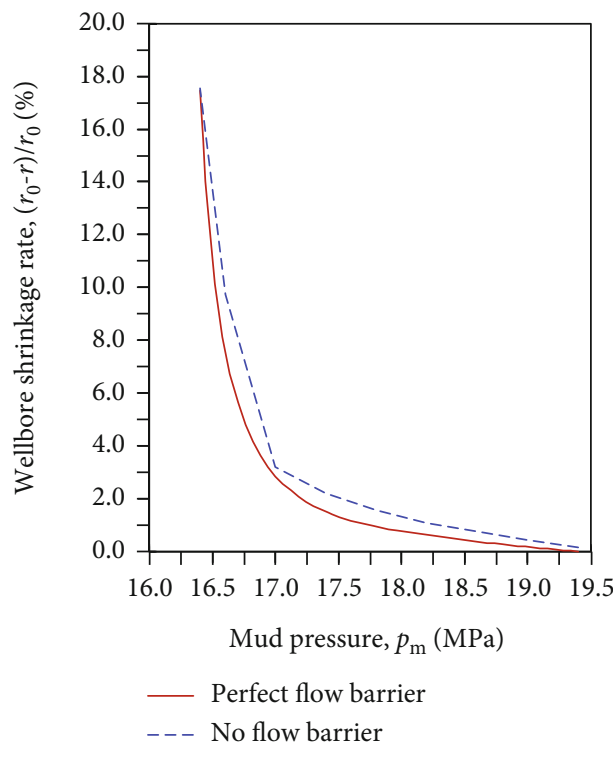

(a)

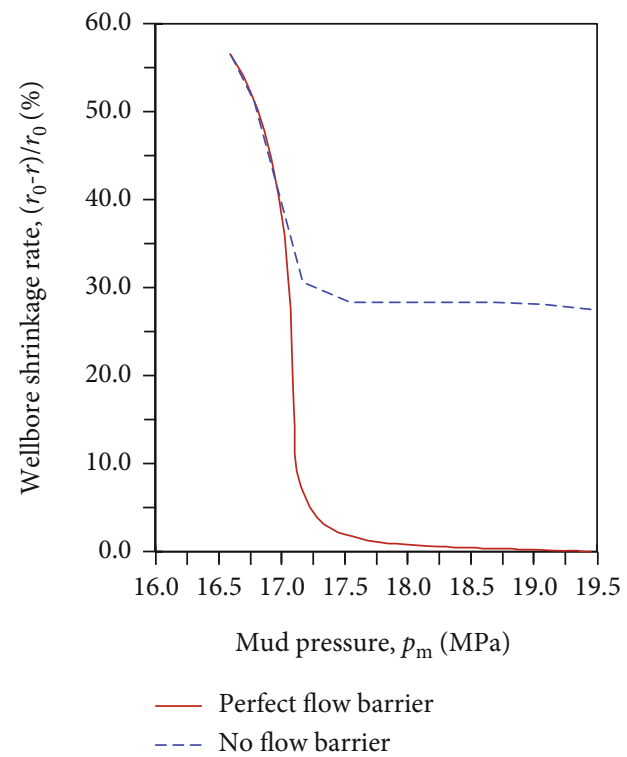

(b)

FIGURE 8: Wellbore shrinkage rate $\left(r_{0}-r\right) / r_{0}$ varying with mud pressure $p_{\mathrm{m}}$ : (a) with plastic compaction; (b) without plastic compaction. 


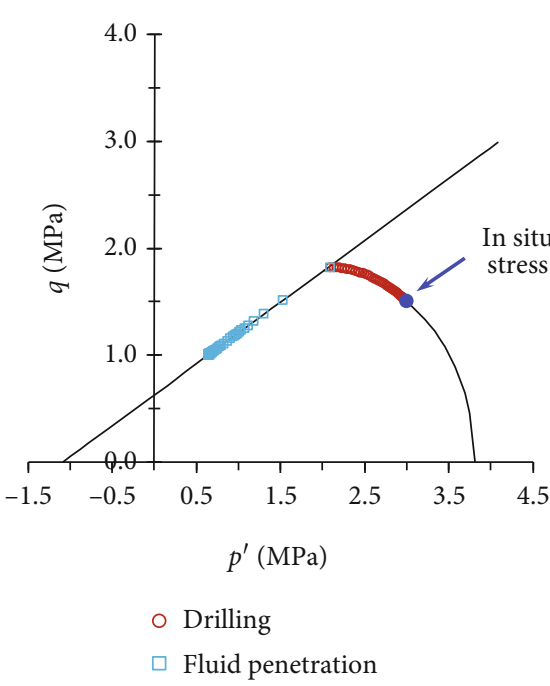

(a)

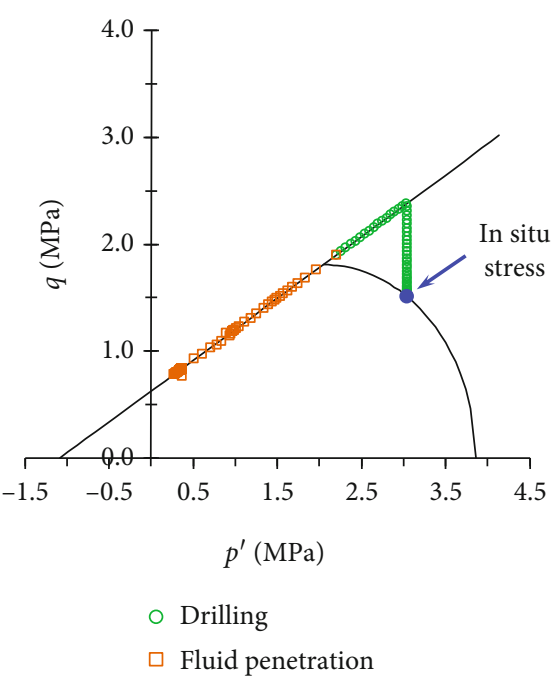

(b)

FIGURE 9: Effective stress paths experienced by a point on the wellbore surface during the drilling process and the ensuing fluid penetration process: (a) with plastic compaction; (b) without plastic compaction (no flow barrier and $p_{\mathrm{m}}$ of $17.8 \mathrm{MPa}$ ).

flow barrier case. From this figure, it can be observed that, if plastic compaction is considered, fluid penetration and pore pressure change within the near-wellbore region does not generate noticeable additional deformation of the wellbore. Increasing the mud pressure can effectively control the wellbore shrinkage. However, if plastic compaction is not considered, it seems that fluid penetration and the resulted pore pressure increase within the near-wellbore region will enhance the shear yielding of the formation and thus cannot reduce the wellbore shrinkage through increasing the mud pressure. For the specific case considered here, without considering plastic compaction of the formation, the wellbore shrinkage rate will remain about $30 \%$ even a mud pressure equal to the in situ horizontal stress is used. The results presented here again demonstrate the necessity of considering the plastic compaction capability of the formation during the wellbore stability analysis of shallow sediments in deepwater.

Figure 9 depicts the stress paths experienced by a point during the drilling with a mud pressure of $17.8 \mathrm{MPa}$ and the ensuing fluid penetration process. During the drilling process, if plastic compaction is considered, the wellbore undergoes only plastic compaction and no plastic shear occurs due to the fact that a relatively high mud pressure $17.8 \mathrm{MPa}$ is used. In contrast, if plastic compaction is not considered, the wellbore undergoes elastic deformation first and then plastic shear deformation. During the fluid penetration process, for both of the two cases, the mean effective stress decreases with increasing pore pressure and thus incurs or enhances the plastic shear deformation. It seems from Figure 9 that mean effective stress decreases more if plastic compaction is not considered, which may be responsible for the larger wellbore shrinkage rate in Figure 8.

4.2. Stability of the Wellbore in Deepwater Shallow Sediments under Mud Pressures Higher Than the In Situ Horizontal Stress. Fracturing of wellbore due to high mud pressure has always been a concern during the drilling of deepwater oil/- gas wells due to the low overburden stress. As mentioned in Introduction, several empirical models have been developed for predicting the fracturing pressure of deepwater wells [5, $19,20]$. Some of these works have assumed that fracturing of shallow sediments in deepwater behaves similarly to fracturing of stiff rocks [5] and predicted the fracturing pressure based on this assumption. However, deepwater shallow sediments generally feature capability of plastic compaction and low shear strength. Mechanisms and characteristics of fracturing of the wellbore in deepwater shallow sediments have not been clearly unveiled yet. Here, using the poroelastoplastic model, we simulate the deformation and failure responses of the wellbore to high mud pressures and try to understand the possible mechanisms of fracturing of wellbores in deepwater shallow sediments.

Under perfect flow barrier condition, with increasing mud pressure, it has been evidenced in some physical experiments that cavity expansion instead of fracturing may happen for wellbores in weakly consolidated or unconsolidated formations [30]. Our analysis results seem to support this experimental observation. Presented in Figure 10 are the wellbore expansion rates varying with mud pressures larger than the in situ horizontal stress. From Figure 10, it can be seen that, if plastic compaction is taken into account, the wellbore only expands mildly at relatively low mud pressures. However, with further increasing mud pressure, the wellbore expands more and more rapidly, and the deformed wellbore radius could be 3.5 times the initial wellbore radius under a mud pressure of $25.38 \mathrm{MPa}$, exhibiting typical characteristic of cavity expansion. From Figure 10, it can also be noted that, if plastic compaction is not considered, the wellbore expansion rate will always be mild, e.g., 10\% for a mud pressure of $25.38 \mathrm{MPa}$, which is far less than that with plastic compaction being considered.

Shown in Figure 11 are the effective stress paths in the $p^{\prime}-q$ plane experienced by a point on the wellbore surface during the drilling process, while Figure 12 presents the 


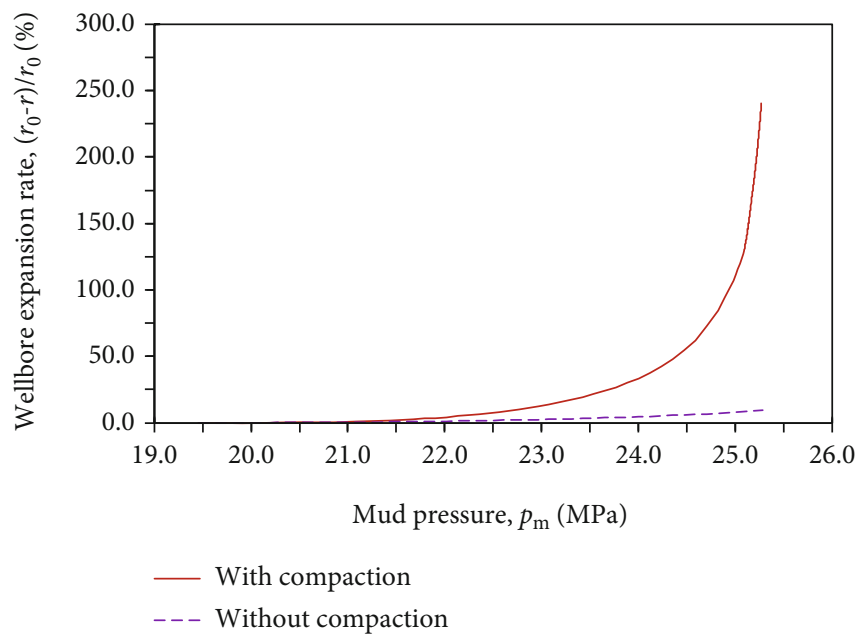

FIGURE 10: Wellbore expansion rate $\left(r-r_{0}\right) / r_{0}$ varying with the mud pressure $p_{\mathrm{m}}$ (perfect flow barrier).

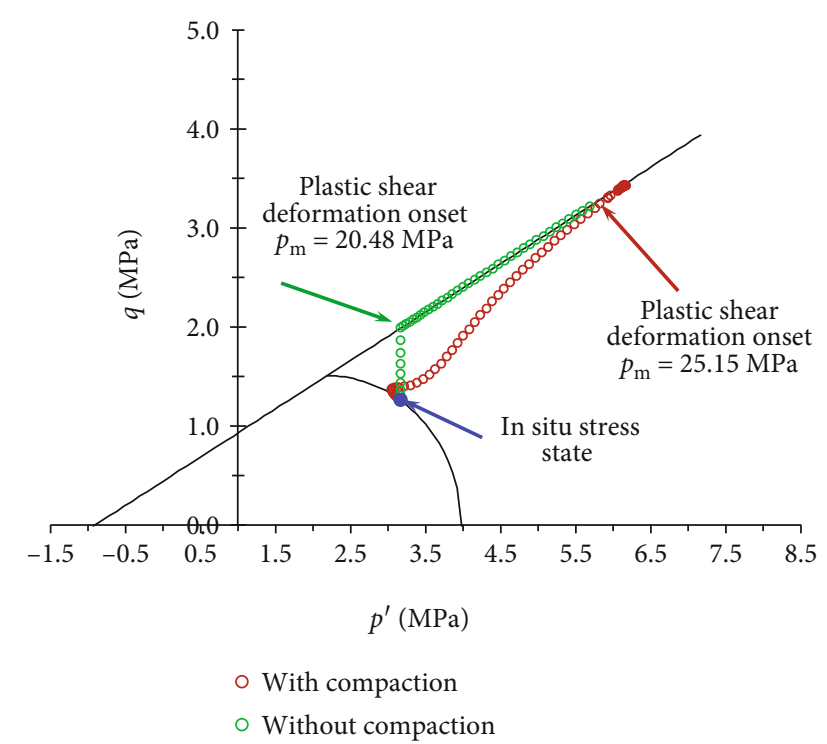

FiguRE 11: Effective stress paths experienced by a point on the wellbore surface during the drilling process (perfect flow barrier and $p_{\mathrm{m}}$ of $25.25 \mathrm{MPa}$ ).

evolution of the three effective principal stress component at the same point. The final mud pressure $p_{\mathrm{m}}$ is $25.25 \mathrm{MPa}$, and the perfect flow barrier is modelled. From Figure 11, one can see that, if plastic compaction is accounted for, the stress path firstly follows the cap field surface, which means that the near-wellbore formation undergoes plastic compaction as the support pressure increases from 19.4 MPa. In this process, both the hoop effective stress $\sigma_{\theta}^{\prime}$ and the vertical effective stress $\sigma_{z}^{\prime}$ decrease first and then increase. When the support pressure increases to a value of $25.15 \mathrm{MPa}$, the stress path hits the Drucker-Prager shear yield surface, indicating that plastic shear deformation initiates at the wellbore surface. In contrast, if plastic compaction of the formation is not considered, again the stress path goes upward vertically before reaching the Drucker-Prager shear yield surface, which implies that the mean effective stress does not change while the deviatoric stress increases continuously. During this elastic deformation process, the hoop effective stress $\sigma_{\theta}^{\prime}$ decreases linearly while the vertical effective stress $\sigma_{z}^{\prime}$ remains constant. When the support pressure is increased to the value of $20.48 \mathrm{MPa}$, the stress path reaches the Drucker-Prager shear yield surface, inducing plastic shear deformation within the near-wellbore region. After that, both the hoop effective stress $\sigma_{\theta}^{\prime}$ and the vertical effective stress $\sigma_{z}^{\prime}$ increase as the support pressure further decreases.

It should be noticed from Figure 12 that, for the case of perfect barrier considered here, all the three effective principal stress components (radial stress, hoop stress, and vertical stress) remain compressive, and no tensile stress presents at the wellbore during the whole process of increasing the mud pressure. Thus, from these analysis results, it can be inferred that if the penetration of drilling fluid into the formation is completely prevented, no fracturing will occur within the near-wellbore region even high mud pressure is employed. Instead, substantial plastic deformation and expansion of the wellbore may happen, as depicted in Figure 13. In this figure, it is shown that, for a mud pressure of $25.13 \mathrm{MPa}$, only wellbore expansion occurs due to plastic compaction, and the deformed wellbore radius is 2.2 times the original radius. However, if the mud pressure is increased to $25.33 \mathrm{MPa}$, the wellbore expands to 3 times its original size and strain localization bands emanating from the wellbore appear due to the combined effect of plastic shear yielding and plastic compaction.

If penetration of drilling fluid into the near-wellbore region is possible, the mud pressure within the nearwellbore region will increase, and thus, the situation will be different. Figure 14 depicts the distributions of the pore pressure and effective principal stresses along the radial direction for several mud pressures. Plastic compaction is considered in the modeling. It can be found that high pore pressure exists within the near-wellbore region due to drilling fluid penetration. It is also noted from this figure that, under high mud pressures (e.g., 23.2 $\mathrm{MPa}$ and 23.6 MPa), shear dilation 


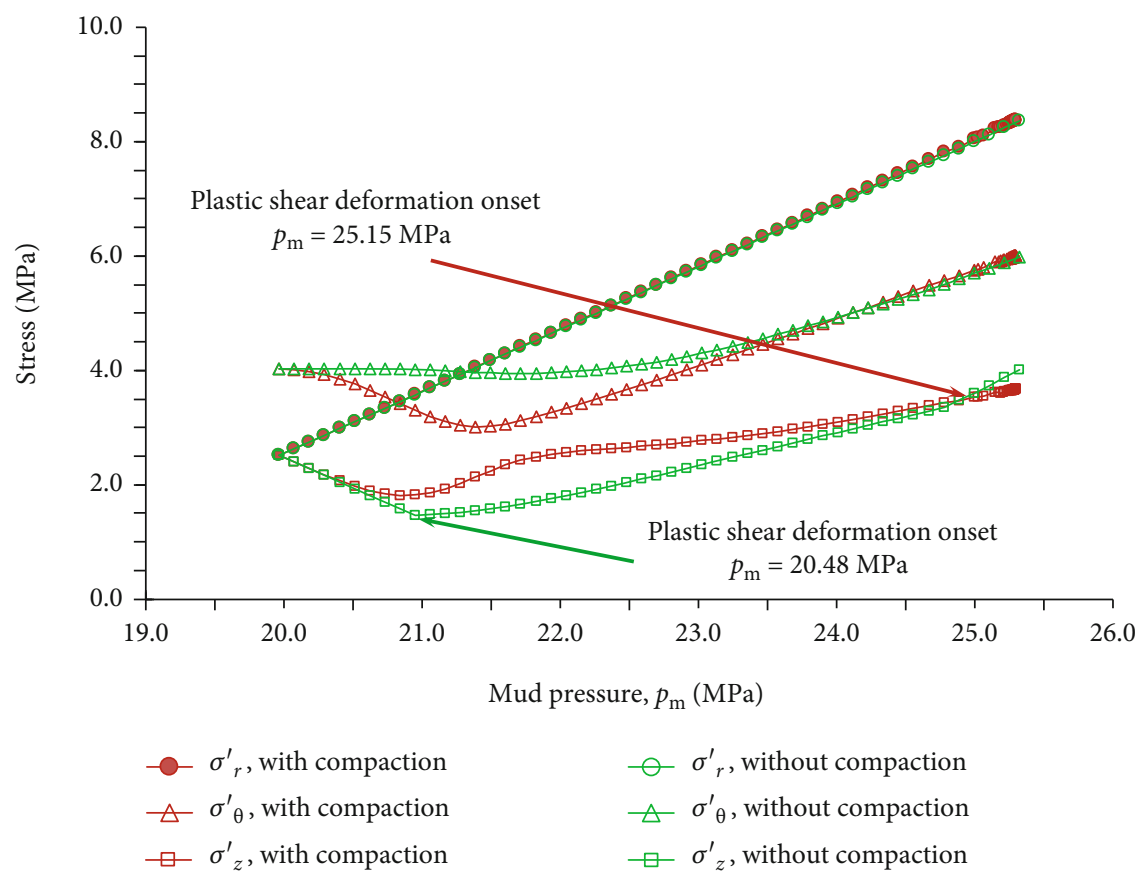

FIGURE 12: Effective stress evolution at a point on the wellbore surface during the drilling process (perfect flow barrier and $p_{\mathrm{m}}$ of $25.25 \mathrm{MPa}$ ).

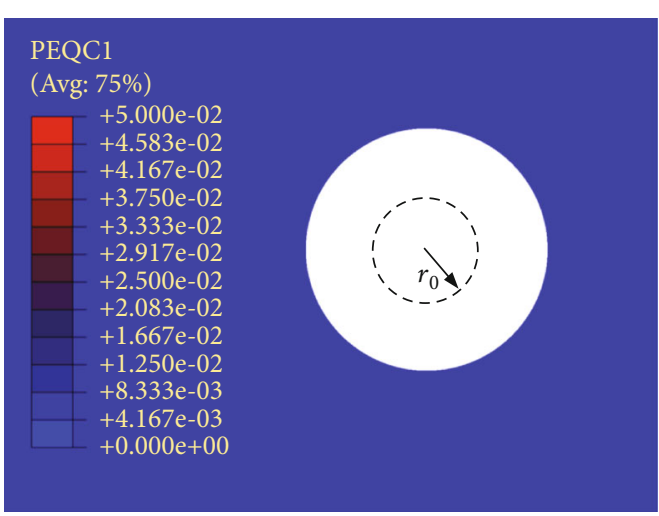

(a)

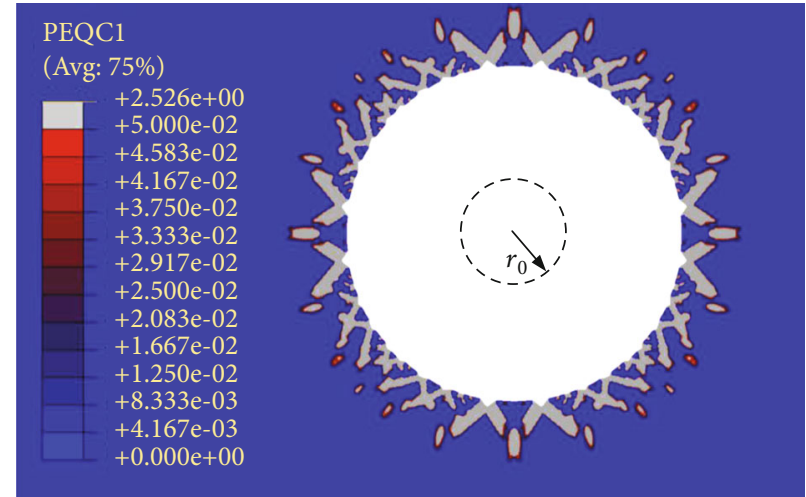

(b)

FIGURE 13: (a) Wellbore expansion only $\left(p_{\mathrm{m}}\right.$ is $25.13 \mathrm{MPa}$ ). (b) Wellbore expansion accompanied by strain localization bands ( $p_{\mathrm{m}}$ is 25.33 MPa).

will induce remarkable permeability increase and influence the pore pressure distribution. From Figures 14(b)-14(d), it is evidenced that the radial effective stress $\sigma_{r}^{\prime}$ and the vertical effective stress $\sigma_{z}^{\prime}$ remain compressive although the mud pressure is increased to as high as $23.2 \mathrm{MPa}$. In contrast, when the pressure is increased to be higher than $20.8 \mathrm{MPa}$, tensile hoop stress develops at the wellbore and thus fracturing will initiate at the wellbore surface. The radius of the fracturing zone increases from 1.8 to 5.3 times the original wellbore radius as the mud pressure increases from $20.8 \mathrm{MPa}$ to $23.2 \mathrm{MPa}$. The mud pressure of $20.8 \mathrm{MPa}$ is close to the overburden stress of $20.9 \mathrm{MPa}$; i.e., the fracturing pressure is close to the overburden stress, which is a typical phenomenon for deepwater drilling [18].
Presented in Figure 15 are the effective stress paths in the $p^{\prime}-q$ plane experienced by a point on the wellbore surface during the drilling process and ensuing fluid penetration process. The mud pressure $p_{\mathrm{m}}$ is $21.6 \mathrm{MPa}$, and the no flow barrier is modelled. From Figure 15, one can see that, during the drilling process, the near-wellbore formation undergoes plastic compaction as the support pressure increases from 19.4 MPa to 21.6 MPa. After drilling, fluid penetrates into the near-wellbore region, leading to reduction of both mean effective stress and deviatoric stress. Then, the stress path hits the Drucker-Prager yield surface and plastic shear deformation occurs. With further increasing pore pressure, the hoop stress becomes tensile and thus fracturing occurs along the radial direction. 

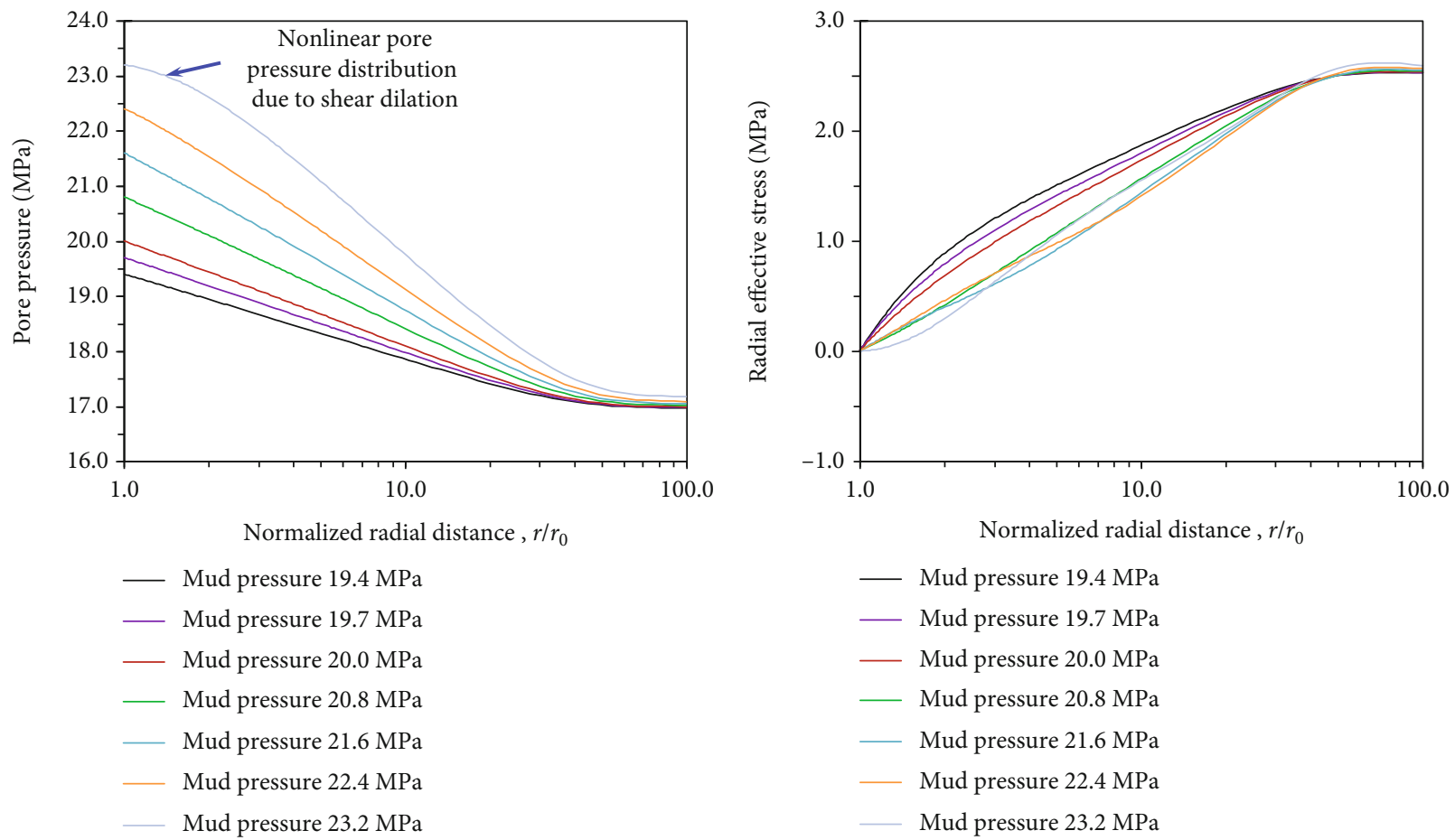

(a)
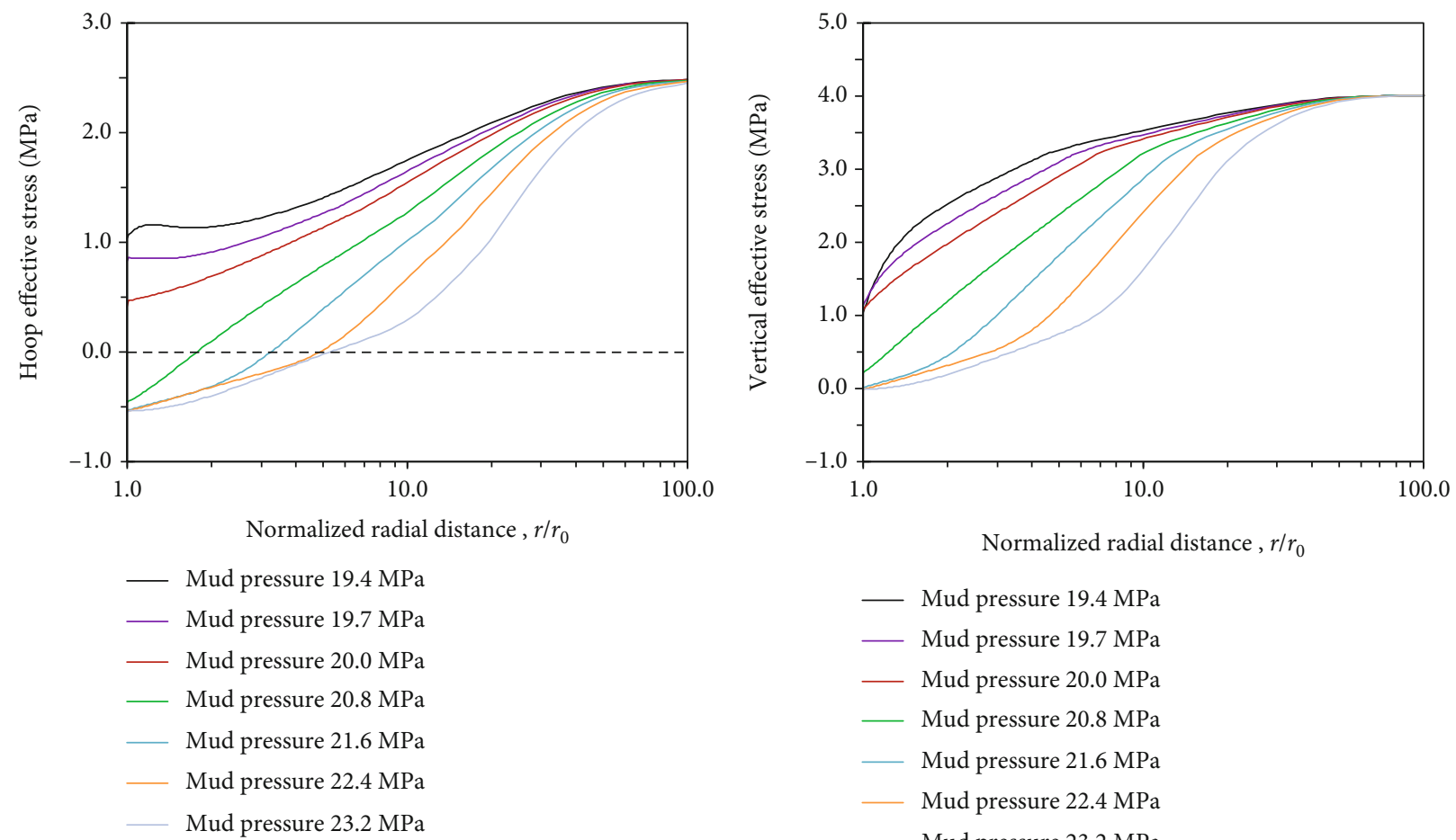

(c)

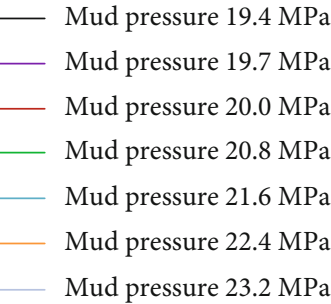

(d)

FIGURE 14: Distributions of pore pressure and effective principal stresses along the radial direction for high mud pressures (no flow barrier).

From the above analysis results in this section, it can be concluded that for shallow sediments in deepwater, if penetration of drilling fluid into the formation is prevented, fracturing of the wellbore may not occur even if the mud pressure is high. Instead, high mud pressure may cause cavity expansion phenomenon at the wellbore; i.e., the wellbore will expand greatly due to the high mud pressure [31]. On the other hand, if drilling fluid can penetrate into the formation, 


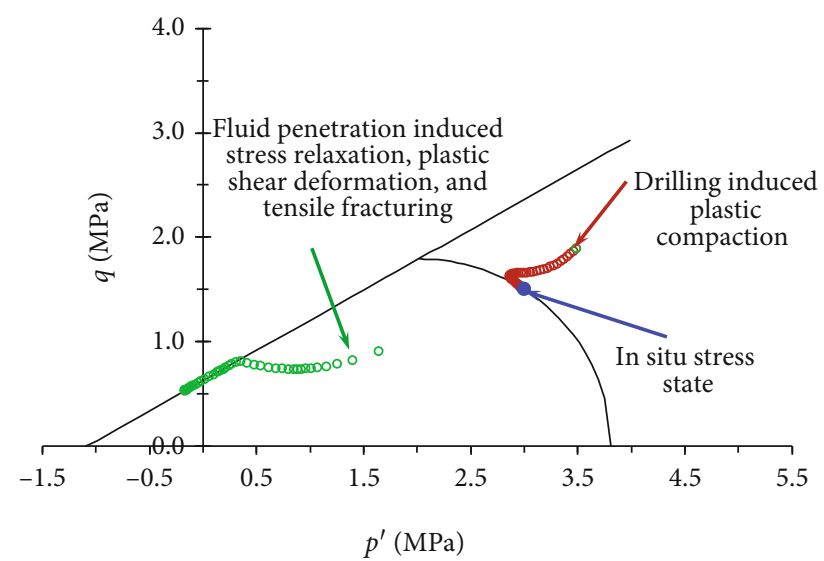

○ Drilling

○ Fluid penetration

FIGURE 15: Effective stress paths experienced by a point on the wellbore surface during the drilling process and ensuing fluid penetration process (no flow barrier and $p_{\mathrm{m}}$ of $21.6 \mathrm{MPa}$ ).

high pore pressure within the near-wellbore region can result in tensile hoop stress at the wellbore and thus leads to fracturing of the wellbore.

\section{Conclusions}

In this paper, a poro-elastoplastic numerical model has been developed to investigate and explore the stability characteristics of the wellbore in shallow sediments of deepwater oil/gas wells. Since the shallow sediments in deepwater are generally weakly consolidated or even unconsolidated, they may exhibit substantial plastic compaction deformation under high mean stress, besides the plastic shear deformation under high deviatoric stress. Thus, in this paper, we employ a frequently used constitutive relation in the soil mechanics, i.e., the Drucker-Prager/cap plasticity model to more appropriately characterize the mechanical behavior of the shallow sediments. Possible penetration of drilling fluid into the formation has also been considered in the model. Using this model, we numerically investigate the stability of the wellbore in deepwater shallow sediments under both low mud pressure condition and high mud pressure condition. The following conclusions can be drawn from the investigations:

(1) Under mud pressures lower than the in situ horizontal stress, the rock formation within the nearwellbore region firstly experiences some plastic compaction deformation and then plastic shear deformation. Excessive wellbore shrinkage may occur if the mud pressure is too low, which may cause problems for tripping and subsequent cementing job. It seems that fluid penetration and pore pressure change within the near-wellbore region does not generate noticeable additional deformation of the wellbore. Increasing the mud pressure can effectively control the wellbore shrinkage. However, if plastic compaction is not considered in the model, fluid penetration and the resulted pore pressure increase within the near-wellbore region will enhance the shear yielding of the formation and lead to uncontrolled wellbore shrinkage even with high mud pressure. The results demonstrate the necessity of considering the plastic compaction capability of the formation during the wellbore stability analysis of shallow sediments in deepwater

(2) Under mud pressures lower than the in situ horizontal stress, if penetration of drilling fluid into the formation is prevented, fracturing of the wellbore may not occur although the mud pressure is very high. Instead, high mud pressure will cause cavity expansion phenomenon at the wellbore; i.e., the wellbore will expand substantially due to plastic compaction and the deformed wellbore radius could be several times larger than the initial wellbore radius. However, if drilling fluid can penetrate into the formation, high pore pressure will develop within the nearwellbore region, resulting in tensile hoop stress at the wellbore and thus fracturing of the wellbore along the radial direction

The numerical modeling work presented in this paper is an initial attempt to explore the stability characteristics of the wellbore in deepwater shallow sediments. By considering the coupled hydromechanical processes and complex constitutive relation, we try to include the major mechanisms that may influence the stability of the wellbore in deepwater shallow sediments. However, due to the difficulty in obtaining samples of shallow sediments, some of the parameters still cannot be determined accurately. In the future, more laboratory experimental researches on the mechanical behaviors on the deepwater shallow sediments are needed to provide more accurate parameters and better predictions on the wellbore stability can be achieved, which will be helpful in the future development of oil/gas resources in deepwater.

\section{Data Availability}

The readers can send emails to the corresponding author to obtain all the data related to the findings in this paper.

\section{Conflicts of Interest}

The authors declare that they have no conflicts of interest.

\section{Acknowledgments}

The authors wish to acknowledge the financial support from the Natural Science Foundation of China (No. 52074313), the Science Foundation of China University of Petroleum, Beijing (No. ZX20200116), and the National Science and Technology Major Project (2017ZX05032004-003).

\section{References}

[1] H. S. Pettingill and P. Weimer, "Worlwide deepwater exploration and production: past, present, and future," The Leading Edge, vol. 21, no. 4, pp. 371-376, 2002. 
[2] P. Weimer and H. S. Pettingill, "Global overview of deep-water exploration and production," Studies in Geology, vol. 56, pp. 711, 2007.

[3] C. Yan, J. Deng, X. Lai, X. Li, and Y. Feng, "Borehole stability analysis in deepwater shallow sediments," Journal of Energy Resources Technology, vol. 137, article 012901, 2015.

[4] L. A. S. Rocha, P. Junqueira, and J. Roque, "Overcoming deep and ultra deepwater drilling challenges," in Offshore Technology Conference Houston, TX, offshore technology conference, Houston, TX, USA, May 2003.

[5] B. S. Aadnoy, "Geomechanical analysis for deep-water drilling," in IADC/SPE Drilling Conference, pp. 441-456, Society of Petroleum Engineers, Dallas, TX, USA, 1998.

[6] W. Bradley, "Failure of inclined boreholes," Journal of Energy Resources Technology, vol. 101, no. 4, pp. 232-239, 1979.

[7] Y. Ding, X.-J. Liu, and P.-Y. Luo, "Investigation on influence of drilling unloading on wellbore stability in clay shale formation," Petroleum Science, vol. 17, no. 3, pp. 781-796, 2020.

[8] P. Papanastasiou and A. Zervos, "Wellbore stability analysis: from linear elasticity to postbifurcation modeling," International Journal of Geomechanics, vol. 4, no. 1, pp. 2-12, 2004.

[9] P. Charlez, "The impact of constitutive laws on wellbore stability: a general review," SPE Drilling \& Completion, vol. 12, no. 2 , pp. 119-128, 1997.

[10] S. Chen and Y. Abousleiman, "Wellbore stability analysis using strain hardening and/or softening plasticity models," International Journal of Rock Mechanics and Mining Sciences, vol. 93, pp. 260-268, 2017.

[11] Z. Zheng, "Integrated borehole stability analysis-against tradition," SPE/ISRM Rock Mechanics in Petroleum Engineering Trondheim, Norway, 1998pp. 395-402, Society of Petroleum Engineers, 1998.

[12] S. Chen, Y. Abousleiman, and K. Muraleetharan, "Closedform elastoplastic solution for the wellbore problem in strain hardening/softening rock formations," International Journal of Geomechanics, vol. 12, pp. 494-507, 2011.

[13] E. Detournay and C. Fairhurst, "Two-dimensional elastoplastic analysis of a long, cylindrical cavity under nonhydrostatic loading," International Journal of Rock Mechanics and Mining Sciences \& Geomechanics Abstracts, vol. 24, no. 4, pp. 197-211, 1987.

[14] P. McLellan and Y. Wang, "Predicting the effects of pore pressure penetration on the extent of wellbore instability: application of a versatile poro-elastoplastic model," in Rock Mechanics in Petroleum Engineering Delft, pp. 205-214, The Netherlands, Society of Petroleum Engineers, 1994.

[15] A. L. Muller, E. do Amaral Vargas, L. E. Vaz, and C. J. Goncalves, "Three-dimensional analysis of boreholes considering spatial variability of properties and poroelastoplasticity," Journal of Petroleum Science and Engineering, vol. 68, no. 3-4, pp. 268-276, 2009.

[16] Y. Wang and M. Dusseault, "Borehole yield and hydraulic fracture initiation in poorly consolidated rock strata-part II. Permeable media," International Journal of Rock Mechanics and Mining Sciences \& Geomechanics Abstracts, vol. 28, no. 4, pp. 247-260, 1991.

[17] C. Yan, J. Deng, L. Hu, and B. Yu, "Fracturing pressure of shallow sediment in deep water drilling," Mathematical Problems in Engineering, vol. 2013, Article ID 492087, 8 pages, 2013.
[18] B. Yu, C. Yan, J. Deng, S. Liu, Q. Tan, and K. Xiao, "Evaluation and application of wellbore stability in deep water," Oil Drilling \& Production Technology, vol. 33, pp. 1-4, 2011.

[19] E. Kaarstad and B. S. Aadnoy, "Improved prediction of shallow sediment fracturing for offshore applications," SPE Drilling \& Completion, vol. 23, no. 2, pp. 88-92, 2008.

[20] L. A. Rocha and A. T. Bourgoyne, "A new simple method to estimate fracture pressure gradient (includes associated paper 37685)," SPE Drilling \& Completion, vol. 11, no. 3, pp. 153159, 1996.

[21] B. S. Aadnøy and M. Belayneh, "Elasto-plastic fracturing model for wellbore stability using non-penetrating fluids," Journal of Petroleum Science and Engineering, vol. 45, no. 34, pp. 179-192, 2004.

[22] A. Inderbitzen, Deep-Sea Sediments: Physical and Mechanical Properties, Media, Springer Science \& Business, 2013.

[23] C. Lee, T. S. Yun, J.-S. Lee, J. J. Bahk, and J. C. Santamarina, "Geotechnical characterization of marine sediments in the Ulleung Basin, East Sea," Engineering Geology, vol. 117, no. 1-2, pp. 151-158, 2011.

[24] O. Coussy, Poromechanics, John Wiley \&Sons, New York, NY, USA, 2004.

[25] E. Fjar, R. M. Holt, A. Raaen, R. Risnes, and P. Horsrud, Petroleum Related Rock Mechanics, Elsevier, Amsterdam, 2008.

[26] S. Helwany, Applied Soil Mechanics with ABAQUS Applications, John Wiley \& Sons, New Jersey, USA, 2007.

[27] D. Simulia, Abaqus 6.13 user's manual, vol. 305, Dassault Systems, Providence, RI, 2013.

[28] W. R. Bryant, W. Hottman, and P. Trabant, "Permeability of unconsolidated and consolidated marine sediments, Gulf of Mexico," Marine Georesources \& Geotechnology, vol. 1, no. 1, pp. 1-14, 1975.

[29] R. Ewy, "Yield and closure of directional and horizontal wells," International Journal of Rock Mechanics and Mining Sciences \& Geomechanics Abstracts, Elsevier, vol. 30, no. 7, pp. 10611067, 1993.

[30] B. Bohloli and C. J. de Pater, "Experimental study on hydraulic fracturing of soft rocks: influence of fluid rheology and confining stress," Journal of Petroleum Science and Engineering, vol. 53, no. 1-2, pp. 1-12, 2006.

[31] S. Chen and Y. Abousleiman, "Exact drained solution for cylindrical cavity expansion in modified cam clay soil," Geotechnique, vol. 63, no. 6, pp. 510-517, 2013. 